\title{
Treating osteoporosis
}

\author{
Akhil Gupta \\ Advanced trainee in genera \\ medicine ${ }^{l}$

\section{Lyn March \\ Consultant rheumatologist ${ }^{1}$ \\ Liggins professor ${ }^{2}$ \\ 'Royal North Shore Hospital \\ Sydney \\ ${ }^{2}$ Rheumatology \\ and Musculoskeletal \\ Epidemiology \\ Northern Clinical School \\ University of Sydney}

\section{Key words}

bisphosphonates, bone resorption inhibitor, calcium, vitamin D

Aust Prescr 2016;39:40-6

http://dx.doi.org/10.18773/ austprescr.2016.028

\section{SUMMARY}

Osteoporotic fractures are common resulting in increased morbidity and mortality. Exercise can help prevent osteoporosis. It can also benefit patients with osteoporosis, but the exercises must be tailored to the patient.

Most Australians should be able to obtain adequate calcium in their diet and vitamin D from the sun. Supplements may be needed in some patients and they are recommended for use with other drugs for osteoporosis.

Bisphosphonates, and in some patients denosumab, are first-line drugs for osteoporosis.

Raloxifene and strontium ranelate can be considered in patients who cannot take bisphosphonates or denosumab. Teriparatide is reserved for patients with severe osteoporosis and the use of strontium ranelate is declining because of cardiovascular safety concerns.

\section{Introduction}

Osteoporosis is a common systemic skeletal condition among older people. Currently, 2.2 million Australians have osteoporosis and, for those aged 50 and over, up to one in four men and two in five women will experience a minimal trauma fracture. ${ }^{1}$ Retrospective data show that fewer than $20 \%$ of these patients are investigated or treated for osteoporosis. Fractures cause significant pain, disability, reduced quality of life and even premature death. ${ }^{2}$ In economic terms, the cost of osteoporosis to the Australian community is projected to be $\$ 33.6$ billion in the decade 2012-22. ${ }^{3}$ There is some international evidence that early detection and treatment of osteoporosis in both men and women is cost-effective..$^{4-6}$

\section{Exercise}

Exercise can delay the onset of osteoporosis. There is strong evidence that 'impact exercises' in children such as hopping, skipping and jumping can lead to higher peak bone mass in adulthood. ${ }^{7,8}$ Impact exercises are also beneficial for middle-aged and older adults for increasing or preventing age-related bone loss. Although the gains in bone mass are promising, there is insufficient evidence to suggest exercise might reduce fractures.

The frequency and severity of falls may be reduced by exercises that maintain muscle strength, muscle mass, flexibility, mobility, balance and ease of movement. For people with established osteoporosis, any exercise that promotes these characteristics is recommended. The Box lists exercises according to their 'osteogenic' profile and more detailed information is available at www.osteoporosis.org.au/exercise. Specifically, weight-bearing aerobic exercises and progressive resistance training improve bone mineral density. ${ }^{7-11}$ Any recommendation for exercise must be tailored to the individual. For example, in patients who have already sustained osteoporotic fractures, moderateto high-impact activities may be unsuitable. Patients

\section{Box The impact of exercises on bone health}

\begin{tabular}{|c|c|c|c|}
\hline Highly osteogenic & Moderately osteogenic & Low osteogenic & Non-osteogenic* \\
\hline Basketball, netball & Running, jogging & Leisure walking & Swimming \\
\hline Impact aerobics & Brisk walking, hill walking & Lawn bowls & Cycling \\
\hline Dancing, gymnastics & Resistance training & Yoga, pilates, tai chi & \\
\hline Tennis & Stair climbing & & \\
\hline Skipping with a rope & & & \\
\hline
\end{tabular}


with asymptomatic vertebral fractures can be at risk of further vertebral fractures and exercises involving forward flexion of the spine should be avoided. However these patients could benefit from postural strengthening exercises.

\section{Calcium}

Adequate body calcium is crucial to prevent bone loss and fracture. The recommended dietary intake of calcium is between 1000 and $1300 \mathrm{mg}$ per day, depending on age and sex. It is recommended that people get this through their diet by selecting foods that are naturally high in calcium, and including foods that have had calcium added. A dietary calcium calculator is available on the International Osteoporosis Foundation website.*

Most Australians do not reach the recommended dietary intake so daily supplements of $500-600 \mathrm{mg}$ of calcium are sometimes needed. This is because calcium supplementation, especially when combined with vitamin $\mathrm{D}$, can reduce the rate of bone loss and fracture in people who are deficient in dietary calcium such as the frail elderly. Calcium supplementation in these people is also thought to optimise the effectiveness of osteoporosis treatments including bisphosphonates, strontium ranelate, denosumab, teriparatide and selective oestrogen receptor modulator therapy.

The controversy regarding the safety of calcium supplements has not yet been resolved. There is some concern regarding a possible increase in the rate of myocardial infarction, ${ }^{12-14}$ however this has not been confirmed by other research. ${ }^{15,16} \mathrm{~A}$ large European study appeared to show increased rates of myocardial infarction in people taking calcium supplements, but not in people who achieved their calcium intake through diet alone. ${ }^{17}$ Taken as currently recommended, combined calcium and vitamin D supplements seem safe and effective for most people who require them. The risk of heart attack and stroke will be the subject of ongoing research.

\section{Vitamin D}

Small amounts of vitamin D are found in some foods, but most adults are unlikely to get more than $5-10 \%$ of their requirement from food. Australians receive most of their vitamin $D$ from direct sunlight. To maintain adequate vitamin $D$, those with fair skin need only expose the arms for 6-7 minutes mid-morning or mid-afternoon outdoors on most days during the Australian summer. Up to 30 minutes exposure will be required in winter. Advice regarding time of day and duration of exposure varies with latitude. A randomised trial of sunlight exposure in residential

${ }^{*}$ www.iofbonehealth.org/calcium-calculator aged-care facilities in Sydney found that compliance with the duration and amount of sunlight exposure required to reach optimal vitamin $\mathrm{D}$ concentrations was low. ${ }^{18}$ Darker skinned people require 3-6 times longer exposure. Window glass, full-coverage clothing and sunscreen inhibit transmission of ultraviolet B and thus synthesis of vitamin D in the skin. Synthesis of vitamin $D$ in the skin also becomes less efficient in older people.

If indicated, vitamin D is best measured at the end of winter or in early spring, when serum 25-hydroxyvitamin D is lowest. Optimal mineral metabolism, bone density and muscle function are achieved when serum 25-hydroxyvitamin $D$ is greater than $50 \mathrm{nmol} / \mathrm{L}$. If testing is carried out at the end of summer, the concentration should be $10-20 \mathrm{nmol} / \mathrm{L}$ higher.

Evidence suggests that $31 \%$ of Australians are vitamin D deficient. ${ }^{19}$ In older people, deficiency is associated with loss of lower extremity muscle mass, strength and impaired balance. Rates of deficiency are higher in southern Australia compared to northern Australia, and in the winter months, $50 \%$ of all Australian women are vitamin D deficient. ${ }^{19}$ Improving vitamin $D$ status reduces the risk of falls and fractures in older people, ${ }^{20,21}$ particularly when combined with adequate calcium. ${ }^{22}$

\section{Prevention of vitamin D deficiency}

To prevent vitamin $D$ deficiency in people who receive less than optimal sun exposure, supplementation is recommended:

- at least $600 \mathrm{IU}$ per day for people under 70

- at least 800 IU per day for people over 70

- 1000-2000 IU per day may be required for sun avoiders or those at high risk of deficiency.

Higher doses are needed if there is vitamin $D$ deficiency (Table 1). For all individuals taking a vitamin D supplement, a daily intake of $1000-1300 \mathrm{mg}$ calcium, ideally dietary calcium, should be encouraged. Vitamin D status should be re-assessed 3-5 months after commencing supplements as the full increase in serum 25-hydroxyvitamin D may not be seen until this time. Although there is no definitive evidence, it

Table 1 Treatment of vitamin D deficiency

\begin{tabular}{|c|c|c|}
\hline Vitamin D status & $\begin{array}{l}\text { 25-hydroxyvitamin D } \\
\text { (end of winter) }\end{array}$ & $\begin{array}{l}\text { Recommended vitamin D } \\
\text { supplementation }\end{array}$ \\
\hline Mild deficiency & $30-49 \mathrm{nmol} / \mathrm{L}$ & 1000-2000 IU per day \\
\hline Moderate deficiency & $12.5-29 \mathrm{nmol} / \mathrm{L}$ & \multirow{2}{*}{$\begin{array}{l}3000-5000 \text { IU per day (for 6-12 weeks) } \\
\text { followed by maintenance dose of } \\
1000-2000 \text { IU per day }\end{array}$} \\
\hline Severe deficiency & $<12.5 \mathrm{nmol} / \mathrm{L}$ & \\
\hline
\end{tabular}


is recommended that calcium and vitamin D status be checked annually in patients undergoing treatment for osteoporosis.

There are very few adverse effects related to vitamin D supplementation. When combined with calcium, there is a small risk of hypercalcaemia, which may lead to hypercalciuria and nephrolithiasis.

\section{Drugs for osteoporosis}

When considering, and before starting, therapies ensure that all patients have adequate vitamin $D$ and calcium concentrations and that any secondary causes for osteoporosis have been managed. The Figure provides an algorithm for the management of established osteoporosis.

\section{Fig. Osteoporosis drug treatment algorithm}

Denosumab (PBS streamlined)

- 60 mg subcutaneous every 6 months recommended for 3 years total then re-assess

- Can be used in renal impairment without dose adjustment

- Osteonecrosis of the jaws has been seen, but rare

- Consider dental assessment before therapy
Established osteoporosis (men and women)

T-score $<-2.5$ in patients 70 or older OR minimal trauma fracture in patients $>50$ years

\section{Corticosteroid-induced osteoporosis}

T-score -1.5 or less on corticosteroids OR patient will receive $7.5 \mathrm{mg}$ daily of prednisolone for 3 months or more (stop treatment when corticosteroid treatment complete)
Bisphosphonates (PBS streamlined)

- Limited use in renal impairment (not recommended when eGFR $<35 \mathrm{~mL} / \mathrm{min} / 1.73 \mathrm{~m}^{2}$ )

- Osteonecrosis of the jaws has been seen, but rare

- Consider dental assessment before therapy

- Gastrointestinal adverse effects can be intolerable with oral drugs

\section{First-line treatment}

vitamin $\mathrm{D}$ and calcium before therapy (to avoid hypocalcaemia that may occur after treatment)

Failure of first-line therapy and/or alternative therapies
Teriparatide

- PBS streamlined for specialist physicians

- Patient very high risk for fracture

- Must have T-score -3.0 or less AND two or more fractures due to minimal trauma AND at least one of those fractures occurring after 12 months of other antiresorptive treatment

\section{Strontium ranelate}

- PBS streamlined if previous fracture

- Mechanism unknown

- Changes in bone density difficult to interpret and inaccurate

- Safety concerns are limiting its use - particularly increased risk of myocardial infarction contraindicated in all patients with a history of ischaemic heart disease, peripheral vascular disease and stroke

- Can increase the incidence and severity of hot flushes 
Bone mineral density testing by dual energy X-ray absorptiometry is recommended every $2-3$ years to help monitor adherence and response to therapy. ${ }^{23}$ More frequent testing every 12 months may be needed if there is a significant change in therapy or the patient's health, or the use of drugs which decrease bone density, for example corticosteroids. ${ }^{23}$ The frequency of bone density testing has come under question. Given that changes to bone density generally occur slowly and allowing for measurement error of the testing, there is little evidence to support annual testing unless there have been major changes in treatment or health status. Some would argue that, once a diagnosis has been made and treatment started, no further testing is necessary given the weak concordance between fracture risk reduction and bone density changes, together with the lack of clear evidence that monitoring improves compliance. ${ }^{24}$ However, most specialists still monitor bone mineral density to gauge adherence and response to treatment after two years and then again at five years to aid decisions about treatment duration.

Table 2 shows the number of patients that must be treated for 36 months in order to prevent one fracture. ${ }^{25-28}$

\section{Oral bisphosphonates}

Bisphosphonates block osteoclast activation and thus slow bone resorption. They slow bone loss, improve bone mineral density and reduce fracture rates. Most bisphosphonates have similar degrees of efficacy, whether they are used intravenously or orally. Headto-head evidence for oral bisphosphonates is lacking.
Oral drugs alendronate and risedronate are the preferred first choice due to their low cost and ease of use with once-weekly dosing. There are other oral bisphosphonates, however they are uncommonly used in the treatment of osteoporosis.

The use of oral bisphosphonates is limited by their adverse effects in renal impairment and they are absolutely contraindicated if the estimated glomerular filtration rate (eGFR) is below $35 \mathrm{~mL} /$ minute $/ 1.73 \mathrm{~m}^{2}$. They also have significant upper gastrointestinal adverse effects. Dysphagia, achalasia, or an inability to remain upright for 30 minutes after tablet ingestion, are absolute contraindications.

\section{Intravenous bisphosphonates}

Intravenous bisphosphonates can overcome the gastrointestinal limitations, however this therapy has other potential adverse effects, notably the risk of flulike reactions with intravenous infusions of zoledronic acid. Other symptoms such as joint and muscle pains can be prolonged. Patients with renal impairment can be at greater risk of these reactions, and in such cases the infusion rate could be reduced. Intravenous bisphosphonates are not recommended when the eGFR is below $35 \mathrm{~mL} /$ minute/1.73 $\mathrm{m}^{2}$. Zoledronic acid has not been tested to any great extent in people with eGFR below $30 \mathrm{~mL} /$ minute $/ 1.73 \mathrm{~m}^{2}$. It may be directly nephrotoxic or may worsen already low bone turnover, however these issues do not appear to be of concern when using the osteoporosis regimen of $5 \mathrm{mg}$ annually. Some clinical experience with zoledronic acid was reported in a cohort with eGFR in the $20-30 \mathrm{~mL} /$ minute/1.73 $\mathrm{m}^{2}$ range without untoward

\section{Table 2 Efficacy of antiresorptive drugs}

\begin{tabular}{|c|c|c|c|}
\hline Drug & $\begin{array}{l}\text { Vertebral fractures } \\
\text { (NNT) }\end{array}$ & $\begin{array}{l}\text { Hip fractures } \\
\text { (NNT) }\end{array}$ & $\begin{array}{l}\text { Patient population studied } \\
\text { (to determine NNT) }\end{array}$ \\
\hline Oral bisphosphonates ${ }^{25}$ & $15-20$ & 91 & $\begin{array}{l}\text { Bone mineral density } \\
\text { (T-score }-2.0 \text { to }-4.0 \text { ) } \\
\text { Low-trauma fracture }\end{array}$ \\
\hline Intravenous bisphosphonates ${ }^{25}$ & 14 & 91 & $\begin{array}{l}\text { Bone mineral density } \\
\text { (T-score }-2.0 \text { to }-4.0 \text { ) } \\
\text { Low-trauma fracture }\end{array}$ \\
\hline Raloxifene $^{26}$ & 29 & $\mathrm{n} / \mathrm{a}$ & $\begin{array}{l}\text { Low bone mineral density } \\
\text { (T-score less than }-2.5 \text { ) } \\
\text { Low-trauma fracture }\end{array}$ \\
\hline Denosumab ${ }^{27}$ & 21 & 200 & $\begin{array}{l}\text { Bone mineral density only } \\
\text { (T-score }-2.5 \text { to }-4.0)\end{array}$ \\
\hline Teriparatide $^{28}$ & 11 & $\mathrm{n} / \mathrm{a}$ & $\begin{array}{l}\text { Low bone mineral density } \\
\text { (mean T-score -2.6) } \\
\text { Low-trauma fracture }\end{array}$ \\
\hline
\end{tabular}


effects although reduced dosing was recommended. As zoledronic acid is renally cleared it has generally been recommended to use a reduced dose or a slower infusion rate in older patients with reduced renal function but no sound evidence exists for this. ${ }^{29}$ A different class of drug that is not affected by renal function, such as denosumab, should be considered. There may also be a slight risk of atrial fibrillation with intravenous zoledronate.

The recommended duration of therapy with oral bisphosphonates is five years and perhaps less (3 years) for intravenous bisphosphonates. ${ }^{30-35}$ Safety data are robust for up to five years of treatment, but extending treatment beyond this has questionable benefit and possible harm. Harms such as osteonecrosis of the jaws and atypical femoral fractures occur very infrequently but are more likely with longer periods of antiresorptive treatment. Osteonecrosis of the jaws is more likely to be seen in patients with cancer receiving frequent doses of bisphosphonates, but other risk factors include dental extractions, dental implants, poorly fitting dentures, and pre-existing dental disease, glucocorticoid use and smoking (see Dental note in this issue).

More research is required to determine optimum duration of bisphosphonate therapy. Each patient should be reviewed after five years and a decision regarding ongoing treatment based on their individual needs and fracture risk profile. If they remain at high risk, most specialists would continue treatment. Treatment may be safely extended or alternative treatments used if:

- the femoral neck T-score** is less than -2.5 without prevalent vertebral fractures

- the femoral neck T-score is less than -2.0 with prevalent vertebral fractures

- there has been a recent fracture.

\section{Denosumab}

Denosumab is a monoclonal antibody that reversibly inhibits bone resorption by reducing osteoclast formation and differentiation while increasing osteoclast apoptosis. It increases bone mineral density at the lumbar spine and hip, and reduces vertebral, non-vertebral and hip fractures. In contrast to bisphosphonates, denosumab can be used in chronic kidney disease, however these patients are particularly at risk of hypocalcaemia so baseline assessment of calcium and vitamin D status should be undertaken before starting therapy. Denosumab's effect will wear off as it does not accumulate.

** T-score: the number of standard deviations that bone mineral density differs from that of a young adult of the same sex
It is therefore given regularly as a six-monthly subcutaneous injection.

\section{Raloxifene}

Raloxifene is a selective oestrogen receptor modulator that reduces postmenopausal bone loss. It reduces the risk of vertebral fractures, but it does not reduce non-vertebral fractures. Raloxifene is an alternative to bisphosphonates or denosumab (if they cannot be tolerated) for women with postmenopausal osteoporosis and is most appropriate for treating younger postmenopausal women with spinal osteoporosis. It increases the incidence of hot flushes, which can be a significant problem in young postmenopausal women. Raloxifene reduces the risk of breast cancer, so it can be considered in women with a high risk of breast cancer. It is, however, known to increase the risk of deep venous thrombosis and other evidence suggests a slightly increased mortality after stroke.

\section{Strontium}

Strontium ranelate reduces bone resorption but its mechanism of action is unknown. A 2008 Cochrane systematic review ${ }^{36}$ of three randomised controlled trials reported a $37 \%$ reduction in vertebral fractures and a $14 \%$ reduction in non-vertebral fractures over three years when strontium was used for established osteoporosis. However, monitoring of bone mineral density while on therapy is difficult to interpret. Up to $50 \%$ of any increase in spinal bone mineral density is due to the atomic weight of strontium and the distribution across the skeleton can be highly variable.

Recent data have raised significant safety concerns, particularly the risk of myocardial infarction. This has curtailed the use of strontium with contraindications in patients with a history of ischaemic heart disease, venous thromboembolism, peripheral vascular or cerebrovascular disease. Strontium use is declining in Australia, but it remains an option for people unable to tolerate other drugs and who have a low cardiovascular risk. ${ }^{37}$

\section{Teriparatide}

Teriparatide is a synthetic form of parathyroid hormone and is the only currently available drug that increases bone formation. As a last line of therapy, teriparatide is used to treat severe osteoporosis and is subsidised in Australia when people continue to fracture despite receiving at least 12 months treatment with first-line therapies.

The rate of vertebral fractures may be reduced by up to $65 \%$. There is an overall reduction in nonvertebral fractures, but the rate of hip fractures is not reduced. 
Contraindications include patients younger than 25 years, known or suspected Paget's disease or previous radiotherapy to bone. Additional contraindications include pre-existing hypercalcaemia, malignancy, kidney disease and primary hyperparathyroidism.

Rat studies have shown a risk of bone sarcomas and this is the only basis for the recommended lifetime exposure to teriparatide being limited to 18 months. Following a course of teriparatide, patients should receive antiresorptive therapy (e.g. raloxifene, a bisphosphonate, denosumab, strontium ranelate) to further increase bone mineral density and maintain the anti-fracture effect.

\section{New drugs}

There are some drugs in development, but their role is currently uncertain. Cathepsin $\mathrm{K}$ is elevated in women with postmenopausal osteoporosis. It is a cysteine protease that cleaves collagen 1, the major collagen type in bone. Bone mass can therefore be preserved by inhibiting cathepsin. Clinical trials with cathepsin $\mathrm{K}$ inhibitors, such as odanacatib, have shown improvements in bone mineral density at the spine and hip. These trials have also found a reduction in bone resorption markers with minimal effect on bone formation.

Another target for therapy is sclerostin. It is produced by osteocytes as a glycoprotein inhibitor of osteoblast signalling. Romosozumab is an anti-sclerostin monoclonal antibody that increased bone formation and bone mineral density in phase I and phase II trials. Further evaluation of the efficacy and safety of this drug in a large phase III controlled study is awaited. These interventions appear to be promising drugs for the treatment of osteoporosis. ${ }^{38,39}$

\section{Conclusion}

As our population ages, osteoporotic fractures are likely to occur more frequently. While preventive measures in the form of exercise are ideal and lifestyle measures play their role, they have limited efficacy in established osteoporosis. There are readily available screening tests along with effective treatments to prevent fractures. All men and women over the age of 50 who sustain a fracture should be assessed for antiresorptive therapy.

Therapy can and should be tailored to the individual. Bisphosphonates are by far the preferred treatment from a cost-effectiveness perspective. Newer treatments are available for patients who cannot use bisphosphonates.

Surveillance for the potential adverse effects of therapy and the need for the continuation of therapy is essential. $<$

Conflict of interest: Lyn March received consultancy fees from Servier.

8. Iuliano-Burns S, Saxon L, Naughton G, Gibbons K, Bass SL. Regional specificity of exercise and calcium during skeletal growth in girls: a randomized controlled trial. Jone Miner Res 2003:18:156-62. http://dx.doi.org/10.1359/ jbmr.2003.18.1.156

9. Shanb AA, Youssef EF. The impact of adding weightbearing exercise versus nonweight bearing programs to the medical treatment of elderly patients with osteoporosis. J Family Community Med 2014;21:176-81. http://dx.doi.org/ $10.4103 / 2230-8229.142972$

10. Zhao R, Zhao M, Xu Z. The effects of differing resistance training modes on the preservation of bone mineral density in postmenopausal women: a meta-analysis. Osteoporos Int 2015;26:1605-18. http://dx.doi.org/10.1007/s00198-015-3034-0

11. Gianoudis J, Bailey CA, Ebeling PR, Nowson CA, Sanders KM, Hill K, et al. Effects of a targeted multimodal exercise program incorporating high-speed power training on falls and fracture risk factors in older adults: a community-based randomized controlled trial. J Bone Miner Res 2014:29:182-91. http://dx.doi.org/10.1002/jbmr.2014

12. Bolland MJ, Avenell A, Baron JA, Grey A, MacLennan GS, Gamble GD, et al. Effect of calcium supplements on risk of myocardial infarction and cardiovascular events: metaanalysis. BMJ 2010;341:c3691. http://dx.doi.org/10.1136/ bmj.c3691

13. Bolland M, Grey A, Reid I. Calcium and cardiovascular risks. Aust Prescr 2013;36:5-8. http://dx.doi.org/10.18773/ austprescr.2013.005

14. Bolland MJ, Grey A, Avenell A, Gamble GD, Reid IR. Calcium supplements with or without vitamin D and risk of cardiovascular events: reanalysis of the Women's Health Initiative limited access dataset and meta-analysis. BMJ 2011;342:d2040. http://dx.doi.org/10.1136/bmj.d2040
SELF-TEST QUESTIONS

True or false?

3. Intravenous bisphosphonates have greater efficacy than oral bisphosphonates.

4. Vitamin D concentrations are best measured at the end of summer.

Answers on page 66 
15. Mursu J, Robien K, Harnack LJ, Park K, Jacobs DR Jr. Dietary supplements and mortality rate in older women: the lowa Women's Health Study. Arch Intern Med 2011;171:1625-33. http://dx.doi.org/10.1001/archinternmed.2011.445

16. Lewis JR, Calver J, Zhu K, Flicker L, Prince RL. Calcium supplementation and the risks of atherosclerotic vascular disease in older women: results of a 5-year RCT and a 4.5-year follow-up. J Bone Miner Res 2011;26:35-41. http://dx.doi.org/10.1002/jbmr.176

17. Li K, Kaaks R, Linseisen J, Rohrmann S. Associations of dietary calcium intake and calcium supplementation with myocardial infarction and stroke risk and overall cardiovascular mortality in the Heidelberg cohort of the European Prospective Investigation into Cancer and Nutrition study (EPIC-Heidelberg). Heart 2012;98:920-5. http://dx.doi.org/10.1136/heartinl-2011-301345

18. Sambrook PN, Cameron ID, Chen JS, Cumming RG, Durvasula S, Herrmann M, et al. Does increased sunlight exposure work as a strategy to improve vitamin D status in the elderly: a cluster randomised controlled trial. Osteoporos Int 2012;23:615-24. http://dx.doi.org/10.1007/ s00198-011-1590-5

19. Daly RM, Gagnon C, Lu ZX, Magliano DJ, Dunstan DW, Sikaris KA, et al. Prevalence of vitamin D deficiency and its determinants in Australian adults aged 25 years and older: a national, population-based study. Clin Endocrinol (Oxf) 2012;77:26-35. http://dx.doi.org/10.1111/j.1365-2265.2011.04320.x

20. Bischoff-Ferrari HA, Dietrich T, Orav EJ, Hu FB Zhang Y, Karlson EW, et al. Higher 25-hydroxyvitamin D concentrations are associated with better lower-extremity function in both active and inactive persons aged $>$ or $=60 \mathrm{y}$. Am J Clin Nutr 2004:80:752-8.

21. Visser M, Deeg DJ, Lips P; Longitudinal Aging Study Amsterdam. Low vitamin D and high parathyroid hormone levels as determinants of loss of muscle strength and muscle mass (sarcopenia): the Longitudinal Aging Study Amsterdam. J Clin Endocrinol Metab 2003;88:5766-72. http://dx.doi.org/10.1210/jc.2003-030604

22. Avenell A, Gillespie WJ, Gillespie LD, O'Connell D. Vitamin D and vitamin $D$ analogues for preventing fractures associated with involutional and post-menopausal osteoporosis Cochrane Database Syst Rev 2009;2:CD000227.

23. The International Society for Clinical Densitometry. 2013 ISCD Official Positions - Adult. ISCD; 2013. www.iscd.org/ official-positions/2013-iscd-official-positions-adult/ [cited 2016 Mar 1]

24. Bell KJ, Hayen A, Macaskill P, Irwig L, Craig JC, Ensrud K, et al. Value of routine monitoring of bone mineral density after starting bisphosphonate treatment: secondary analysis of trial data. BMJ 2009;338:b2266. http://dx.doi.org/10.1136/ bmj.b2266

25. Ringe JD, Doherty JG. Absolute risk reduction in osteoporosis: assessing treatment efficacy by number needed to treat. Rheumatol Int 2010;30:863-9. http://dx.doi.org/10.1007/s00296-009-1311-y

26. Ettinger B, Black DM, Mitlak BH, Knickerbocker RK, Nickelsen T, Genant HK, et al.; Multiple Outcomes of Raloxifene Evaluation (MORE) Investigators. Reduction of vertebral fracture risk in postmenopausal women with osteoporosis treated with raloxifene: results from a 3-year randomized clinical trial. JAMA 1999:282:637-45. http://dx.doi.org/10.1001/jama.282.7.637
27. Cummings SR, San Martin J, McClung MR, Siris ES, Eastell R, Reid IR, et al.; FREEDOM Trial. Denosumab for prevention of fractures in postmenopausal women with osteoporosis. N Engl J Med 2009;361:756-65. http://dx.doi.org/10.1056/ NEJMoa0809493

28. Product information: Forteo (teriparatide [rDNA origin] injection). USA: Eli Lilly and Company; 2012 Mar. https://pi.lilly.com/us/forteo-pi.pdf [cited 2016 Mar 1]

29. Toussaint ND, Elder GJ, Kerr PG. Bisphosphonates in chronic kidney disease; balancing potential benefits and adverse effects on bone and soft tissue. Clin J Am Soc Nephrol 2009;4:221-33. http://dx.doi.org/10.2215/CJN.02550508

30. Black DM, Reid IR, Boonen S, Bucci-Rechtweg C, Cauley JA Cosman F, et al. The effect of 3 versus 6 years of zoledronic acid treatment of osteoporosis: a randomized extension to the HORIZON-Pivotal Fracture Trial (PFT). J Bone Miner Res 2012;27:243-54. http://dx.doi.org/10.1002/jbmr.1494

31. Black DM, Schwartz AV, Ensrud KE, Cauley JA, Levis $S$, Quandt SA, et al.; FLEX Research Group. Effects of continuing or stopping alendronate after 5 years of treatment: the Fracture Intervention Trial Long-term Extension (FLEX): a randomized trial. JAMA 2006;296:2927-38. http://dx.doi.org/ 10.1001/jama.296.24.2927

32. Watts NB, Chines A, Olszynski WP, McKeever CD, McClung MR, Zhou $X$, et al. Fracture risk remains reduced one year after discontinuation of risedronate. Osteoporos Int 2008;19:365-72. http://dx.doi.org/10.1007/ s00198-007-0460-7

33. Schwartz AV, Bauer DC, Cummings SR, Cauley JA, Ensrud KE, Palermo L, et al.; FLEX Research Group. Efficacy of continued alendronate for fractures in women with and without prevalent vertebral fracture: the FLEX trial. J Bone Miner Res 2010;25:976-82. http://dx.doi.org/10.1002/ jbmr.11

34. Harris ST, Watts NB, Genant HK, McKeever CD, Hangartner T, Keller M, et al.; Vertebral Efficacy With Risedronate Therapy (VERT) Study Group. Effects of risedronate treatment on vertebral and nonvertebral fractures in women with postmenopausal osteoporosis: a randomized controlled trial. JAMA 1999;282:1344-52. http://dx.doi.org/10.1001/ jama.282.14.1344

35. Bone HG, Hosking D, Devogelaer JP, Tucci JR, Emkey RD, Tonino RP, et al.; Alendronate Phase III Osteoporosis Treatment Study Group. Ten years' experience with alendronate for osteoporosis in postmenopausal women. N Engl J Med 2004;350:1189-99. http://dx.doi.org/10.1056/ NEJMoa030897

36. O'Donnell S, Cranney A, Wells GA, Adachi JD, Reginster JY. Strontium ranelate for preventing and treating postmenopausal osteoporosis. Cochrane Database Syst Rev 2008;CD005326.

37. Therapeutic Goods Administration. Strontium ranelate (Protos) and risk of adverse events: safety advisory. Canberra: Australian Government Department of Health; 2014 Apr 3. www.tga.gov.au/alert/strontium-ranelateprotos-and-risk-adverse-events-0 [cited 2016 Mar 1]

38. Clarke BL. Anti-sclerostin antibodies: utility in treatment of osteoporosis. Maturitas 2014:78:199-204. http://dx.doi.org/ 10.1016/j.maturitas.2014.04.016

39. Bhutani G, Gupta MC. Emerging therapies for the treatment of osteoporosis. J Midlife Health 2013:4:147-52. http://dx.doi.org/10.4103/0976-7800.118991

\section{FURTHER READING}

Endocrinology Expert Group. Therapeutic Guidelines:

endocrinology. Version 5. Melbourne: Therapeutic Guidelines

Limited; 2014. 